\title{
Advanced Rotorcraft Transmission (ART) Program Summary
}

T.L. Krantz

Propulsion Directorate

U.S. Army Aviation Systems Command

Lewis Research Center

Cleveland, Ohio

and

J.G. Kish

Sikorsky Aircraft

Stratford, Connecticut

Prepared for the 28th Joint Propulsion Conference and Exhibit cosponsored by the AIAA, SAE, ASME, and ASEE Nashville, Tennessee, July 6-8, 1992

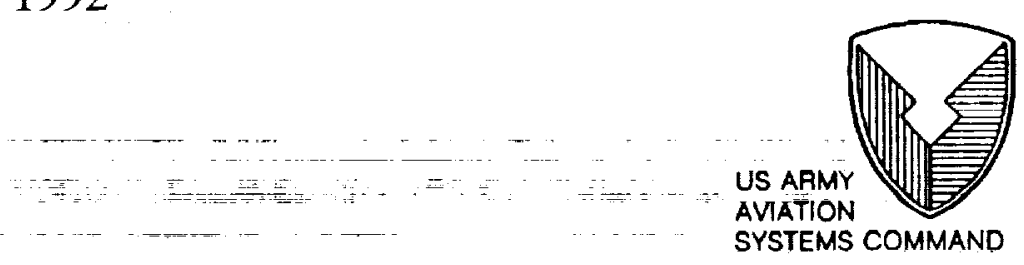

(MASA-TM-105665) AOVANCEO ROTORCRAFT TPANSMISSION (ART) PROGRAM SUMMARY $14 \mathrm{P}$
N92-24984

Unclas 0091253 


\title{
ADVANCED ROTORCRAFT TRANSMISSION (ART) PROGRAM SUMMARY
}

\author{
T.L. Krantz \\ Propulsion Directorate \\ U.S. Army Aviation Systems Command \\ Lewis Research Center \\ Cleveland, Ohio 44135-3191 \\ and \\ J.G. Kish \\ Sikorsky Aircraft \\ Stratford, Connecticut 06601-1381
}

\begin{abstract}
$\underline{\text { Abstract }}$
The Advanced Rotorcraft Transmission (ART) Program was initiated to advance the state-of-the-art for rotorcraft transmissions. The goal of the ART Program was to develop and demonstrate the technologies needed to reduce transmission weight by 25 percent and reduce noise by $10 \mathrm{~dB}$ while obtaining a 5000-hr meantime-between-removal. This paper summarizes the research done at Sikorsky Aircraft under the ART Program. A split path design was selected as best able to meet the program goals. Key component technologies needed for this design were identified, studied, and developed. Two of these technologies are discussed in detail: the load sharing of split path designs including the use of a compliant elastomeric torque splitter and the application of a high ratio, low pitch line velocity gear mesh. Development of an angular contact spherical roller bearing, transmission error analysis, and fretting fatigue testing are discussed. The technologies for a lightweight, quiet, and reliable rotorcraft transmission have been demonstrated.
\end{abstract}

\section{$\underline{\text { Introduction }}$}

The next generation of rotorcraft vehicles will require drive systems that are lighter, quieter, and more reliable. These improvements are needed to increase the vehicle's payload and performance, improve passenger comfort and safety, lower operating costs, and improve readiness. The Advanced Rotorcraft Transmission (ART) Program was initiated to address these needs and advance the state-of-the-art for rotorcraft transmissions. The ART program is an Army funded research pro- gram managed jointly by the Army and NASA. The goal of the ART Program is to develop and demonstrate the technologies needed for rotorcraft transmissions that will be 25 percent lighter and $10 \mathrm{~dB}$ quieter than the state-of-the-art while increasing the mean-time-between-removal to a minimum of $5000 \mathrm{hr}$. The ART program consists of four major contracts. Project status reviews for all four contracts are documented in Refs. 1 to 8 . This article will overview the experiments and analysis phase of the program conducted by Sikorsky Aircraft.

\section{Technology Needs and Research Plan}

The vehicle that defined the transmission requirements was an Advanced Cargo Aircraft (ACA) heavy lift helicopter with a projected 80000 -lb gross weight, 25000 -lb payload, and $500-\mathrm{km}$ mission radius. Many drive system configurations were identified and evaluated against the ART program goals and the requirements of the selected ACA helicopter. The configuration selected as best able to meet the program goals was the split path transmission illustrated in Fig. 1. The important design parameters and resulting characteristics for this transmission are summarized in Table 1. An evaluation of this design predicted that it would meet the goal of a $10-\mathrm{dB}$ noise reduction, be 23 percent lighter than the baseline, and have a 3890-hr mean-time-between-removal. Although the reliability for this design is less than the 5000-hr ART program goal, the 3890-hr figure is approximately four times greater than the baseline and was a difficult goal to achieve for a heavy lift vehicle. The impact of the advanced transmission on vehicle performance and cost was studied. 
One of the results of that study was that this technology would reduce the 35-year life cycle cost of a 600 -vehicle fleet by $\$ 1.7$ billion dollars. A more detailed discussion of the design and how it was selected can be found in Refs. 1, 2, and 10.

The significant characteristics of the selected transmission design are the split path configuration and several key component technologies including:

(1) Composite gearbox housing

(2) Composite drive shafts

(3) High speed spring clutch

(4) High hot hardness steel

(5) Angular contact spherical roller bearings

(6) High reduction ratio gear mesh at the output stage

(7) Wide face width, high contact ratio double helical mesh

(8) Split path load sharing methods

(9) Topologically ground tooth profiles

Items 4 to 9 were selected for study, development, and demonstration in the ART program. A component technology development plan was established that consisted of research areas that were key to the successful advanced transmission development.

Experiments were used to study the fretting characteristics of a high hot hardness steel. A code was developed for analysis and design of angular contact spherical roller bearings with ceramic rollers, and bearings were built and tested in a special test rig. An analytical study investigated how to optimize the gear mesh parameters to minimize transmission error. A half-scale gearbox and test facility were built and tests conducted to study the high contact ratio double helical gear mesh, split path load sharing, transmission error, topological tooth profiling, and design durability. The half-scale gearbox, shown in Fig. 2, duplicates the final two stages of the split path gearbox for one engine path but at one-half geometric scale. One-half scale was chosen to reduce fabrication costs of the hardware and test facility. By using the same speed as the full scale gearbox, reducing the power by one-eighth, and scaling the components by one-half, the tested components experience the same bending stresses, Hertz stresses, and deflections as the full scale design. Also, component life and reliability are the same notwithstanding material allowables based on size effects. However, the sliding velocities of the half-scale gear meshes are half of the full scale components.

The test program for the half-scale gearbox included the following testing:

(1) No load lubrication survey

(2) Gear pattern development and verification

(3) Static and dynamic surveys

(4) $200-\mathrm{hr}$ endurance test

(5) 200-hr, 120-percent overtorque test

The test facility uses two identical gearboxes in a back-to-back, closed loop type arrangement. More detailed descriptions of the development plan, analytical studies, and test facilities have been documented previously. $1,2,9-11$

\section{Research Results}

The experiments and analysis to study and develop the key component technologies have been completed. The technologies for a lightweight, quiet, reliable rotorcraft transmission have been demonstrated. Some results of the research, fully documented in Ref. 10, are summarized here.

\section{Angular Contact Spherical Roller Bearing}

A computer code, SASHBEAN, was developed to assist in the design and analysis of angular contact, spherical roller bearings. For a helicopter application, the angular contact spherical roller bearing must operate at significantly higher speed than in traditional applications. Used on the helicopter gearbox input section, it replaces the current state-of-the-art ball and roller bearing combination.

The SASHBEAN code was used to design a bearing that would support the spiral bevel pinion of the ART transmission. Test bearings were manufactured with two types of rollers; steel and ceramic. Bearings were tested both at nominal operating conditions and at loss of lubricant conditions. The results of endurance testing done at nominal operating conditions showed that the design was durable. Figure 3 illustrates the results 
of loss of lubricant testing for the ceramic bearing compared to an analytical prediction of the maximum bearing temperature. The actual maximum temperature of the tested bearing was somewhat greater than the experimentally measured outer race temperature. The slopes of the plots of analytical data and experimental data are similar.

The cage of the bearing failed 21 min after loss of lubricant. Further design optimization is required to increase the loss of lubricant survivability time to achieve the desired target of $60 \mathrm{~min}$.

\section{Fretting Fatigue}

Fretting fatigue experiments were conducted for a high hot hardness steel, Pyrowear 53, that is a candidate material for gears. Two types of specimens were tested, one plated with thin dense chrome and one without plating. It was found that the plating did not significantly change the fretting fatigue life, and the Pyrowear 53 material has a fretting fatigue life similar to 9310 steel.

\section{Gear Mesh Technology}

The tooth profiles of the half-scale gearboxes were modified to account for deflection under load. The types of modifications used have become feasible only recently with the introduction of computer numerically controlled gear grinding equipment capable of lead and root modification. A finite element analysis of the gearbox housing, shafts, and gears was conducted to determine tooth deflections. The teeth of the gears were coated or plated with silver, copper, gold, black oxide, and blueing to aid in visualization of the tooth contact patterns. The silver and copper plate were most effective for the tooth development process. Strain gage measurements across the face of the teeth were also used to evaluate the load distributions. The gear teeth patterns and strain measurements were analyzed after running under load. The teeth were contacting across the full face width and the strain readings showed good load distribution such that further grinding for pattern development was not required. The capability to obtain proper tooth load distributions without experimental trial and error was demonstrated.
An analysis was conducted to study the tooth load distribution and transmission error of both the second stage high contact ratio spur mesh and the final stage double helical mesh (Fig. 4). The analysis indicated that changes could be made to both meshes that would improve the load distribution. Also, by changing the double helical mesh from the initial herringbone design with aligned left and right hand helixes to one in which the two halves of the double mesh are staggered, the predicted transmission error could be reduced by about 50 percent.

\section{Split Path Load Sharing}

A split path design at the final stage of the gearbox is desired to obtain the advantages of sharing the torque among multiple pinions, as is done in a conventional planetary stage, while also obtaining a larger reduction ratio than is possible for a planetary design. A split path design with a large reduction ratio at the final gear stage weighs less than a planetary design. However, the split path design must have good load sharing between the two power paths. If the torsional stiffness between the torque splitting gear and combining pinion is high compared to the load carried, and manufacturing errors are considered, one of the two power paths will carry more than half of the total power. One method to reduce the load sharing error is to properly index the torque splitting gear and pinion while maintaining precise manufacturing tolerances for machining and assembly. This is feasible using today's manufacturing capabilities but may not be the optimal solution. Other methods have been proposed, including an axially floating quill shaft, torsionally compliant shafts, balancing mechanisms, and laterally compliant bearing supports. These methods may significantly alter the vibration properties of the gearbox. The two methods tested in this program were the use of precise tolerances and the use of a special device to provide torsional compliance.

The device used to provide torsional compliance between the torque splitting gear and pinion, an elastomeric load sharing device, is shown in Fig. 5. Alternate thin layers of nitrile rubber and 
steel are stiff in the direction perpendicular to the laminates but allow large deflections in the parallel direction. The laminates are located at an angle to the axis of rotation on two halves that are bolted together. The laminates are compressed as the two halves are drawn together during assembly. The magnitude of the compressive preload force is important because it controls the magnitude of the friction force between the spur gear and isolator halves. The torque on the gear is transmitted by the frictional forces between these surfaces. Larger preloads create a larger torque capacity, but if the preload is too large the material will yield and fail. The elastomeric torsional isolator shown is about five times more compliant in torsion than an all steel assembly of the same dimensions. The all steel versions were precisely assembled to properly index the two gears on the common shaft. Both designs were tested.

Both methods for torque splitting proved to be feasible. The mean torque carried by the dual paths was equal within 5 percent for both methods. The relationship between the torsional compliance of the dual paths and the precision required in assembly was verified by the experiments. Although both methods were feasible, the behavior observed during the two tests was different.

The transmission error measured at the helical pinion for each of the two tests at identical operating conditions is shown in Fig. 6. One significant difference is that the magnitude of the maximum peak-to-peak transmission error is more than 50 percent less when using the elastomeric isolator. Also, the speed at which the maximum transmission error occurred is different. One would expect that the large compliance of the isolator would shift the resonance condition to a lower frequency. The maximum response, however, occurred at a higher speed with the elastomeric isolator compared to the steel assembly. It is likely that the two-peak responses are two different mode shapes being excited within the speed range shown.

Another observed difference in behavior was that the audible noise produced while testing the elastomeric isolator was significantly less compared to that while using the all steel assemblies. This is consistent with the lower transmission errors that were measured. The elastomers provide a high degree of damping not normally found in helicopter transmission components. More research and study is needed to state conclusively whether the reduction in transmission error and noise was the result of added compliance, added damping, or both.

The transmission error measurements and observed noise difference makes the torsional isolator an attractive option. The isolator also would have the advantage of relaxing costly, precise manufacturing tolerances. However, an unexpected and undesirable characteristic of the present design was discovered during endurance testing. The torque split between the two power paths changed slightly during the testing. It was later verified that the spur gear and isolator halves that make up the isolator assembly had slipped with respect to one another, which affected the torque split. The nitrile rubber and steel have different thermal expansion rates. For the isolator geometry used, as the temperature of the assembly increased, the load in the laminated area increased. A test was conducted by the Lord Corporation, the manufacturer of the load sharing device, where a steel and nitrile rubber laminate was compressed by a predetermined amount and held at that dimension. The test specimen was subjected to temperature cycles while being held at a constant compressed dimension, and the compressive load in the laminate was measured. Figure 6 is a plot of the test results. Note that during the first cycle over a time scale of $600 \mathrm{~min}$, with the temperature and deflection held constant, the compressive load decreased by about 30 percent. Using the results of these tests, the effect of the temperature cycles experienced by the elastomeric torque splitter during testing in the half-scale gearbox was calculated. It was found that under repeated heating and cooling, the preload had decreased significantly enough to reduce the torque capacity below the design torque, and slippage occurred during testing. Furthermore, the assembled preload at room temperature could not be adjusted to compensate for the desired operating temperature range without either reaching a yield stress at the highest temperature or losing needed torque capacity at the lowest temperature. The elastomeric torque 
splitter, in its current configuration, does not have the needed torque capacity over the entire range of temperatures required for a fielded system. However, an alternate temperature compensating design that matches the compliance and damping of the present design may be possible.

\section{High Reduction Ratio Double Helical Gear Mesh}

During a scheduled 150-hr visual inspection of the 200-hr endurance test of the half-scale gearbox, surface distress was discovered on a gear tooth. Examination through the inspection port on the test gearbox revealed a distressed surface condition on one of the two double helical pinions. The distressed area was typical of a spalling type of surface distress. A decision was made to continue testing and monitor the spall to determine propagation rates. An advantage of a double helical mesh with such a high contact ratio as in the ART gearbox (Fig. 4) is that in the event of a surface distress such as that experienced, adjacent teeth will carry the load for a considerable period of time before the tooth becomes totally deteriorated. The 200-hr test was completed and the gearbox disassembled for a closer look at the spall.

The original spall had increased in size from the estimated 0.09 to 0.23 by 0.15 in: in diameter. In addition, another tooth on the same pinion had a smaller spall measuring approximately 0.23 by 0.05 in. The general locations and conditions of the spalled areas are illustrated in Fig. 8.

There was no evidence of other surface distress conditions on the gears of the test or dummy gearboxes. There was a considerable difference in appearance of the teeth of the double helical pinions of the test gearbox compared to the pinions of the dummy gearbox. The teeth of the test gearbox double helical pinions showed a high degree of polish whereas the dummy gearbox showed only a small degree of polish and had a surface finish close to the manufactured condition. The surface finish of the teeth were measured using a Taylor Hobson surface finish measuring machine with a 0.030 -in. cutoff. The surface finish of the test pinion was measured 10 to $17 \mu \mathrm{in}$. rms while the surface finish of the dummy pinion was measured as 21 to $27 \mu \mathrm{in}$. rms.
The operating speed and load of the test and dummy gearboxes are identical since they are connected in a back-to-back arrangement. The direction of rotation of the dummy gearbox is opposite to that of the test gearbox since the dummy gearbox is a driven compared to driving for the test gearbox. However, for the two gearboxes the loaded side of the tooth, load magnitudes, and load directions are identical. The only essential difference between the operating conditions of the test and dummy gearboxes was the separate lubrication systems and operating temperatures. The test gearbox inlet oil was preheated to obtain an average oil outlet temperature of approximately $190^{\circ} \mathrm{F}$ whereas the dummy gearbox had no facility oil heating system. The dummy gearbox oil temperature ran at approximately $120^{\circ} \mathrm{F}$ oil out. With the DOD-L-85734 oil used in both gearboxes, the viscosity of the oil in the test gearbox was estimated to be $5.8 \mathrm{cS}$ and in the dummy gearbox to be $16.5 \mathrm{cS}$. The difference in viscosity is because of the temperature difference.

The evidence of a spalled tooth and polished surfaces, indicating a high degree of working in the test gearbox, and no spalling with much less polishing and wear in the dummy gearbox, along with the factor of differences in lubrication led to an investigation of poor lubricant film thickness or elastohydrodynamic (EHD) film thickness effects as the cause of the surface distress. Most of the work in this area has been related to bearing operation. The theory has been extended to gears by several researchers. An investigation of the literature showed that two basic methods of calculation exist for EHD film thickness in gears. The Cheng, modified Gruben analysis ${ }^{12}$ is easier to use because it makes use of a single lubricant property, the lubricant parameter. The more popular Dowson Higginson ${ }^{13-16,17}$ procedure requires the use of the lubricant absolute viscosity in microreyns and the pressure viscosity coefficient in inches squared per pound.

After the film thickness is calculated, the ratio of film thickness to the composite surface roughness, $\lambda$, is found. When $\lambda$ is equal to 1 , the film thickness is equal to the surface roughness. Thus the surface is just immersed in oil and wear is minimal. As $\lambda$ increases over 1 , the film thickness 
is larger than the surface asperities and the chance of surface distress becomes lower with higher $\lambda$. On the other hand, when $\lambda$ falls below 1 , the peaks of the surface finish will be sticking out of the oil located in the valleys. When $\lambda$ gets very low, as in the ART half-scale testing which was done with a calculated $\lambda$ in the range of 0.2 , the gears are operating in the boundary lubrication regime, and the chance of surface distress increases.

The film thickness is a function of load, speed, and lubricant properties. The most influential parameter in calculated film thickness is speed, or more precisely pitch line velocity. In the ART program, the half-scale gearbox operates at oneeighth power and the same speed as the full scale gearbox, which duplicates the tooth fatigue bending stress, tooth compressive (Hertz) stress, gear tooth deflections, shaft fatigue bending stress, shaft deflection, housing stress, and housing deflections of the full scale gearbox. However, although most important parameters match, the half-scale gearbox pitch line velocity is one-half of the full scale gearbox. In the half-scale ART test, the pitch line velocity of the double helical pinion was $817 \mathrm{ft} / \mathrm{min}$ at 100 percent speed. In comparison, the full scale ACA ART transmission would have twice the pitch line velocity, or $1634 \mathrm{ft} / \mathrm{min}$. Production Sikorsky helicopter output stage pitch line velocities are in the range from 1300 to $1900 \mathrm{ft} / \mathrm{min}$.

From the above discussion, it is seen that the half-scale ART test gearbox has an artificially induced low pitch line velocity compared to what it would be in the full-scale gearbox or compared to other production helicopter output stages.

Since velocity is the most influential parameter in the calculation of EHD film thickness, the ART half-scale test gearbox has an artificially low EHD film thickness. Figure 9 is a plot of calculated EHD film thickness for the half-scale gearbox as a function of temperature. As seen, the film thickness at the $120^{\circ} \mathrm{F}$ temperature of the dummy gearbox was approximately twice that of the test gearbox operating at $190^{\circ} \mathrm{F}$.

Gears are capable of operating in the boundary lubrication regime for many cycles, as evidenced by typical helicopter output stages which have operated without surface distress for millions of flight hours with calculated $\lambda$ ratios in the range of 0.36 to 0.46 . The allowable $\lambda$ ratio was investigated by Wellauer and Holloway ${ }^{18}$ in the 1970's. Unfortunately, little work has been accomplished since. Moreover, the Wellauer and Holloway work was based substantially on test data for through hardened gears along with a limited amount of data for carburized gears. The allowable $\lambda$ ratio versus probability of distress curves that are shown in many references are taken from the original Wellauer and Holloway test data. Carburized gears have a much lower probability of EHD related surface distress than through hardened gears, as evidenced by the limited testing done by Wellauer and Holloway and also by comparing data for successful production helicopter gear output stages to the allowable curve. Figure 10, taken from AGMA Ref. 17, shows a high probability of distress at $\lambda=0.4$ and $2000 \mathrm{ft} / \mathrm{min}$, which is typical for a production helicopter output stage which operates successfully without surface distress. There is a need for more work to be done in this area for carburized gears. The fact that no allowables exist for carburized gears is perhaps a reason why aerospace designers have been reluctant to use EHD analysis as a design tool.

Split path designs have pitch line velocities which are on the low side of current helicopter experience. This is inherent in the design if full advantage is taken of the weight benefit from maximum reduction ratio at the final output stage. If pitting resulting from low EHD oil film becomes a design driver or a source of gearbox removal, there is an easy solution available. The solution is to use an oil having a higher viscosity than currently used in helicopter transmissions. Oil choice has been largely driven by military requirements to use a common oil in the turbine engine and transmission. If this thinking can be reversed, low EHD films will not be a problem for split path transmissions.

\section{Conclusions}

The technologies needed for the next generation rotorcraft transmission have been identified and research conducted in the Advanced Rotorcraft Transmission program. Research has been conducted to develop and demonstrate the technologies required for a transmission that has a 5000-hr 
mean-time-between removal and also is $10 \mathrm{~dB}$ quieter and 25 percent lighter than state-of-the art transmission. The following results were obtained in the ART program research.

1. A split path design was developed that met the program goals for less noise and less weight while obtaining a 3890-hr mean-time-between removal. Two of the new, significant technologies needed for this design are split path load sharing and a high reduction ratio, low pitch line velocity mesh at the final output stage.

2. An angular contact spherical roller bearing was developed and demonstrated. This bearing, with ceramic rollers, ran for $21 \mathrm{~min}$ without oil before failure, about one-third of the desired 60-min target.

3. Thin dense chrome plating does not significantly change the fretting fatigue life of the high hot hardness gear steel Pyrowear 53. The fretting life of the material without plating is similar to 9310 steel.

4. Two methods for achieving an equal torque split in a split path gearbox were tested: precision tolerances and indexing at assembly and a compliant elastomeric torque splitter. Both methods were demonstrated and are feasible.

5. The transmission error and noise from the gearbox were reduced by using the elastomeric torque splitter.

6. The elastomeric torque splitter in its current configuration does not have the needed torque capacity for the entire range of temperatures required for a fielded system.

7. A surface distress failure occurred that is related to the low EHD film thickness of the low pitch line velocity at the final stage mesh of the half-scale gearbox. Surface distress is not likely in the full scale gearbox because the pitch line velocity is double that tested.

8. The calculation techniques for low EHD film thickness have been developed, but the operating conditions where EHD related surface failures will occur are not precisely established for carburized gears.

\section{$\underline{\text { References }}$}

1. Kish, J., "Advanced Rotorcraft Transmission (ART)-Program Status," AIAA Paper 91-1909, June 1991.

2. Kish, J., "Advanced Rotorcraft Transmission (ART) Program Review," Rotary Wing Propulsion Specialists' Meeting; Proceedings, American Helicopter Society, Alexandria, VA, 1990, 11 p.

3. Bossler, R.B., and Heath, G.F., "Advanced Rotorcraft Transmission (ART) Program Status," AIAA Paper 91-1906, June 1991.

4. Bossler, R.B., and Heath, G.F.: "Advanced Rotorcraft Transmission (ART) Program Status," Rotary Wing Propulsion Specialists' Meeting; Proceedings, American Helicopter Society, Alexandria, VA, 1990, 14 p.

5. Henry, Z.S., "Preliminary Design and Analysis of an Advanced Rotorcraft Transmission," AIAA Paper 91-2018, June 1991.

6. Henry, Z.S., "Preliminary Design and Analysis of an Advanced Rotorcraft Transmission," Rotary Wing Specialists' Meeting; Proceedings, American Helicopter Society, Alexandria, VA, 1990, 14 p.

7. Lenski, J.W., and Valco, M.J., "Advanced Rotorcraft Transmission (ART) ProgramBoeing Helicopters Status Report, NASA TM-104474, 1991.

8. Lenski, J.W., "Boeing Helicopters Advanced Rotorcraft Transmission (ART) Program Status," Rotary Wing Propulsion Specialists' Meeting; Proceedings, American Helicopter Society, Alexandria, VA, 1990, 15 p. 
9. Mitchell, Jr., G.D., "Manufacturing

Techniques-Split Torque Path Helicopter Transmission," AHS Paper A-91-47130-5000, 1991, Presented at American Helicopter Society 47th Annual Forum, Phoenix, AZ, May 6-8, 1991, NASA Contract NAS3-25423.

10. Kish, J., "Sikorsky Helicopter Advanced Rotorcraft Transmission Project. Final Report," To be published as NASA CR- , 1992.

11. Hochmann, D., Smith, D., Thomas, J., and Houser, D.R., "Transmission Error and Load Distribution Analysis of Spur and Double Helical Gear Pair Used in a Split Path Helicopter Transmission Design," Presented at AHS Technical Specialists Meeting, Philadelphia, PA, Oct. 15-16, 1991.

12. Mobil EHL Guidebook, Third Ed., Mobil Oil Corp., Fairfax, VA, 1981.

13. Errichello, R.E., "The Lubrication of Gears, Part 1," Gear Technology, Vol. 8, Mar./Apr. 1991, pp. 18-26.
14. Errichello, R.E., "The Lubrication of Gears, Part 2," Gear Technology, Vol. 8, May/June 1991, pp. 18-22.

15. Errichello, R.E., "The Lubrication of Gears, Part 3," Gear Technology, Vol. 8, July/Aug. 1991, pp. 14-22.

16. Errichello, R.E., "The Lubrication of Gears, Part 4," Gear Technology, Vol. 8, Sept./Oct. 1991, pp. 18-25.

17. American National Standard Institute/American GearManufacturers Association, "Fundamental Rating Factors and Calculation Methods for Involute Spur and Helical Gear Teeth," ANSI/AGMA 2001-B88, Sept. 1988.

18. Wellauer, E.J., and Holloway, G.A., "Application of EHD Oil Film Theory to Industrial Gear Drives," Journal of Engineering for Industry, Vol. 98B, No. 2, May 1976, pp. 626-634.

TABLE I.-TRANSMISSION DESIGN PARAMETERS AND SUMMARY

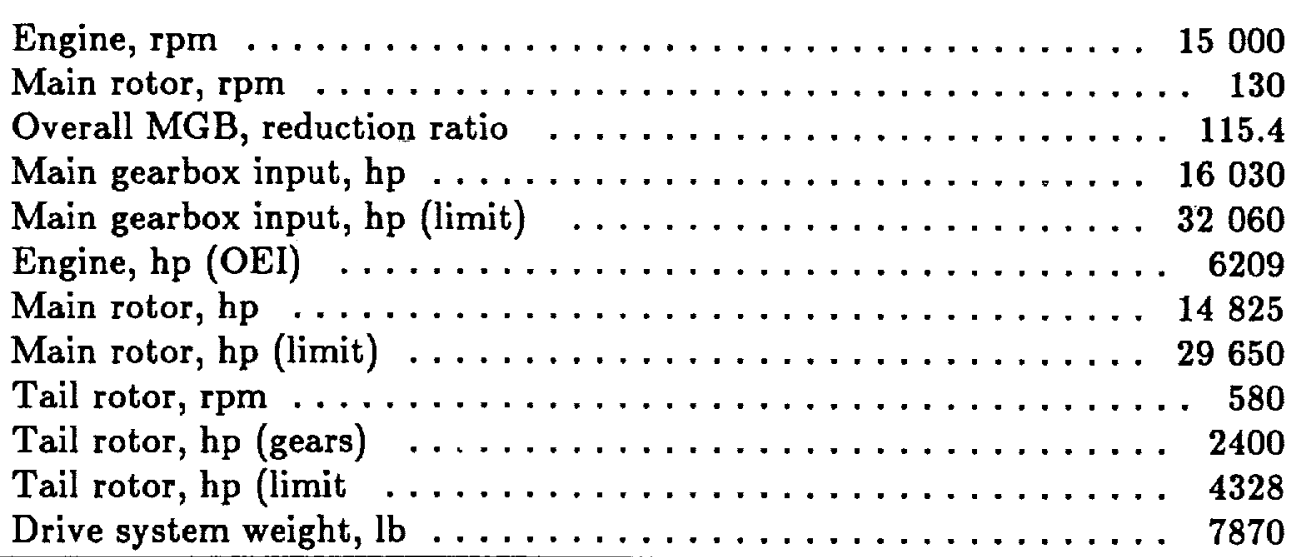




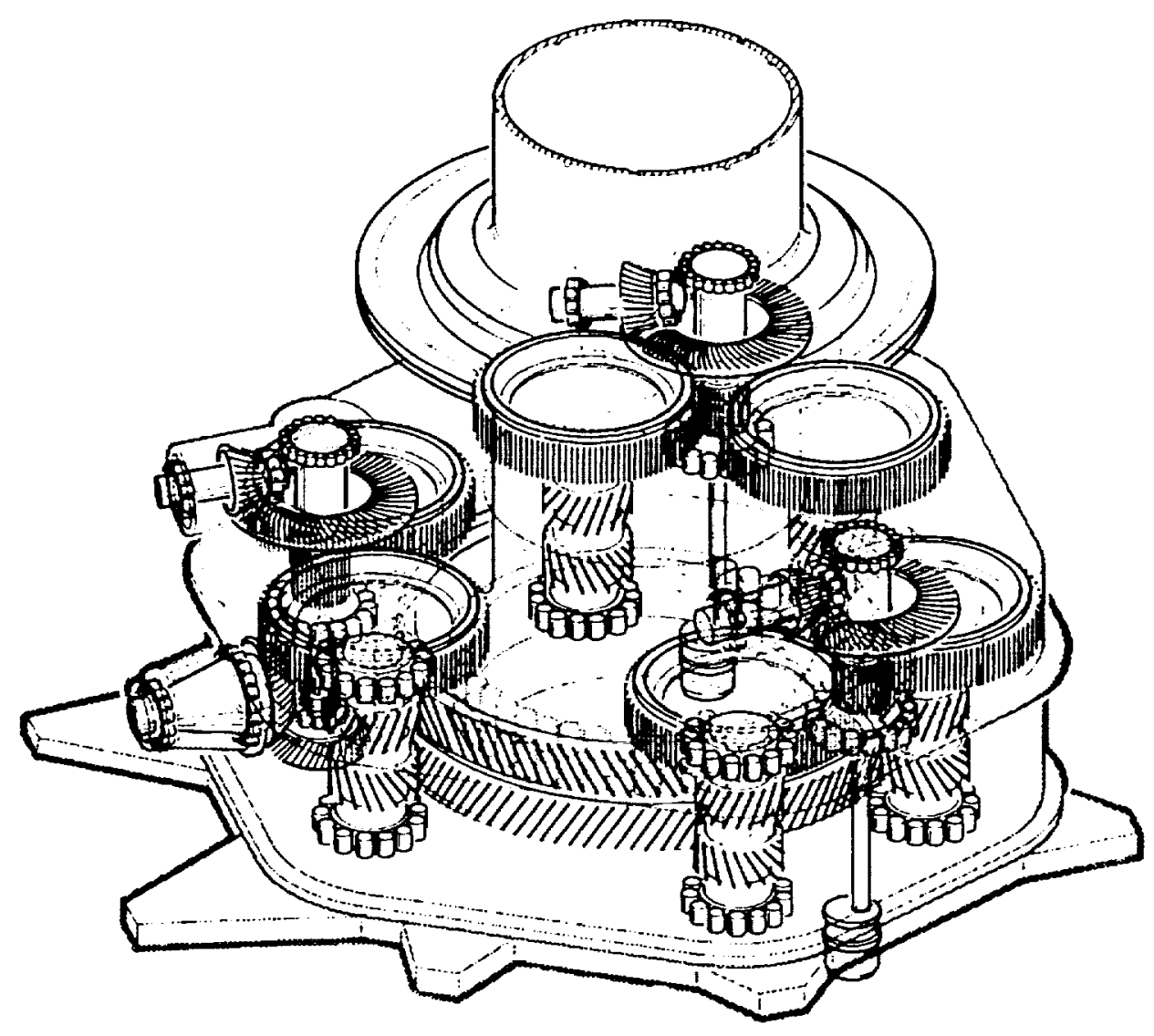

(a) Isometric view.

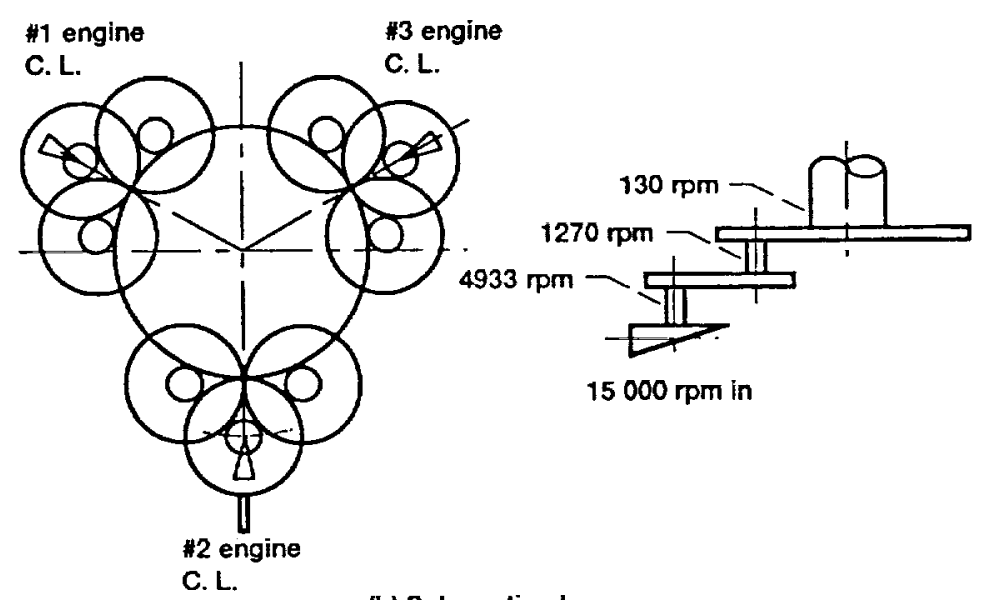

(b) Schematic plan.

Figure 1.-Advanced cargo aircraft split path transmission. 


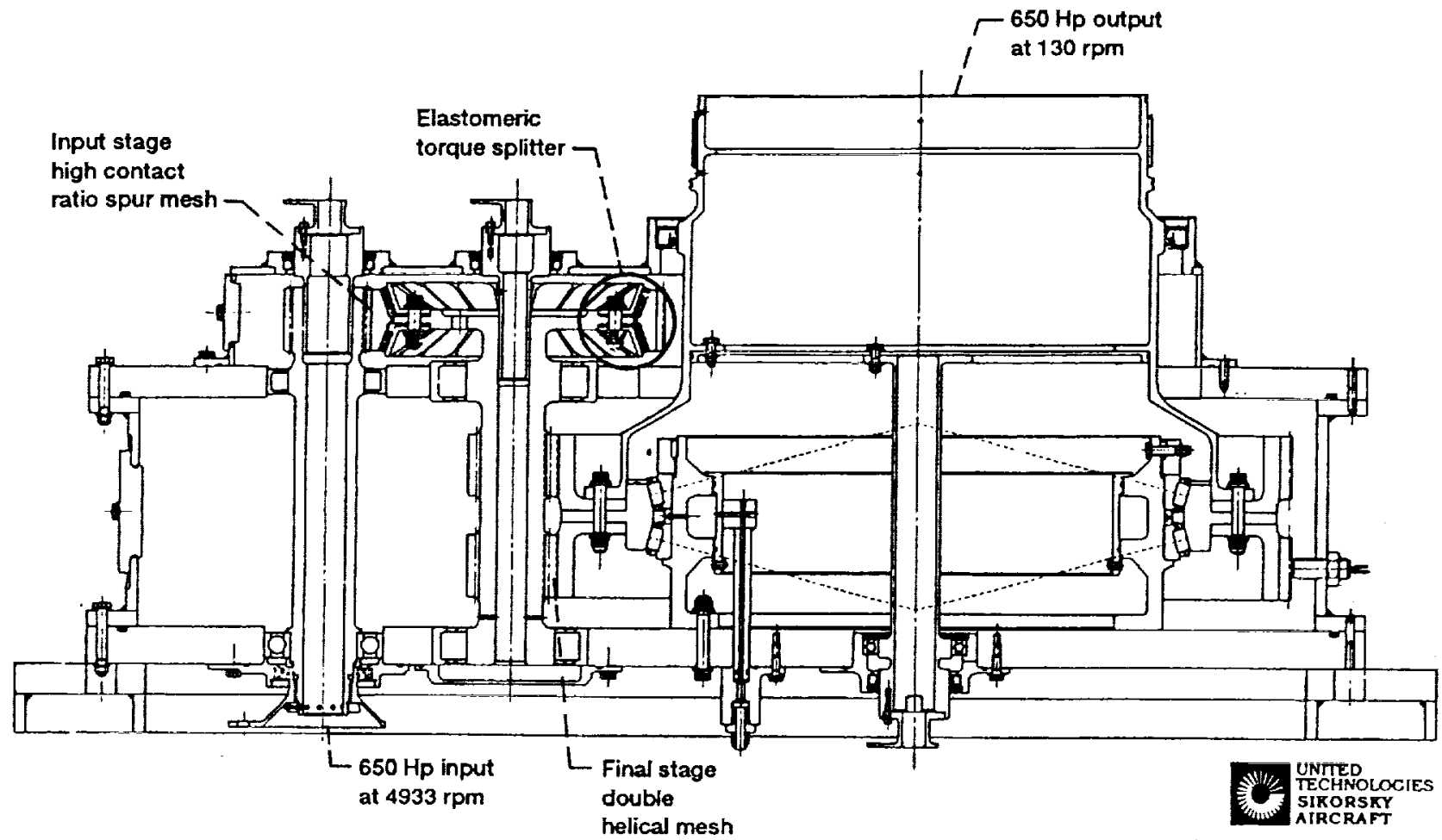

Figure 2.-ART $1 / 2$ scale split torque gearbox.

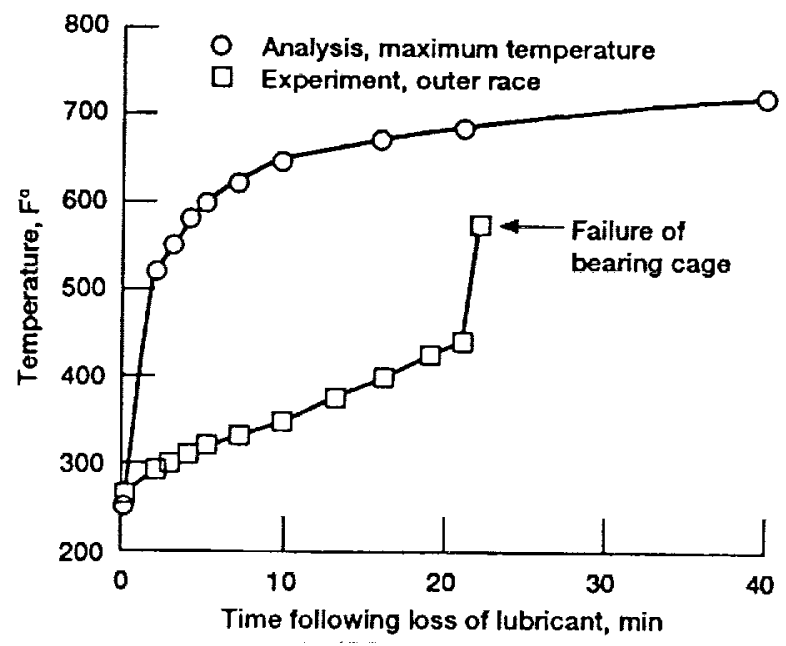

Figure 3.-Loss of lubicant survivability, angular contact, ceramic spherical roller bearing.

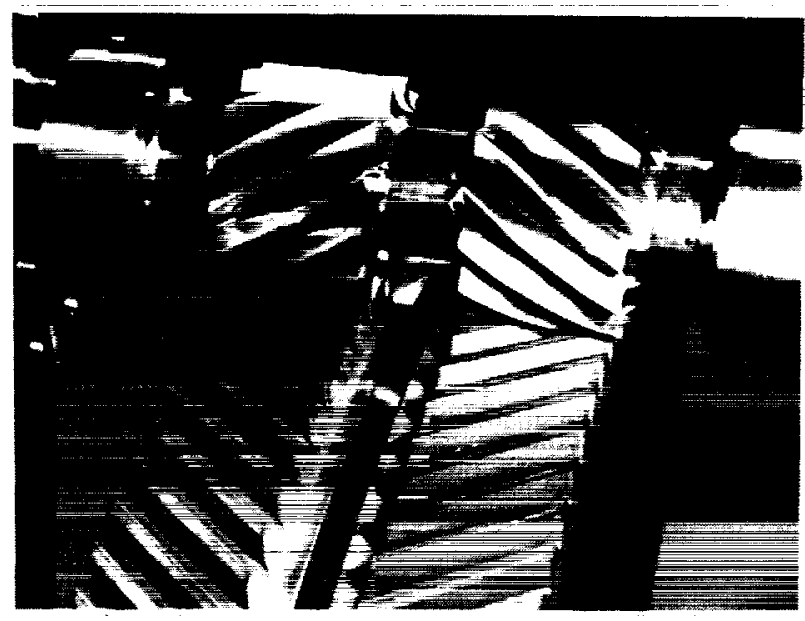

Figure 4.-High reduction ratio double helical gear mesh.

ORIGINAL PAGE

BLACK AND WHITE PHOTOGRAPH 


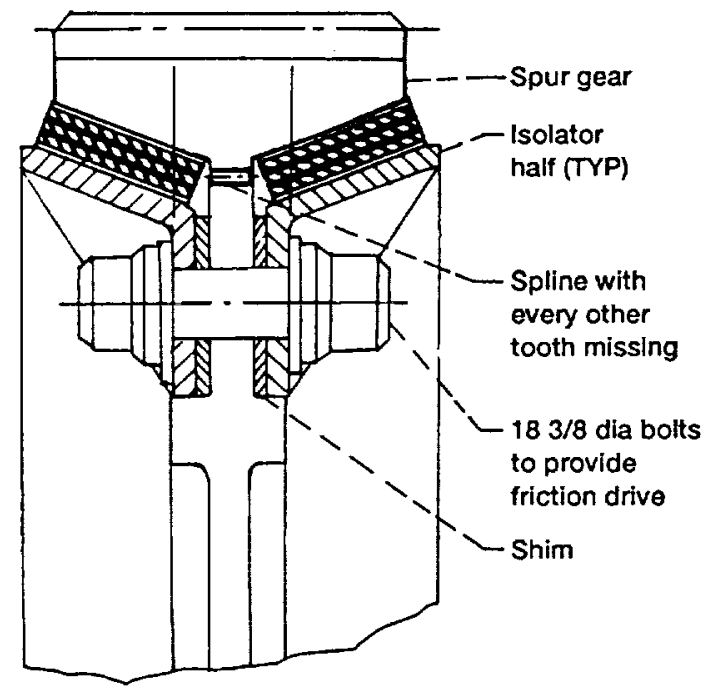

(a) Cross section.

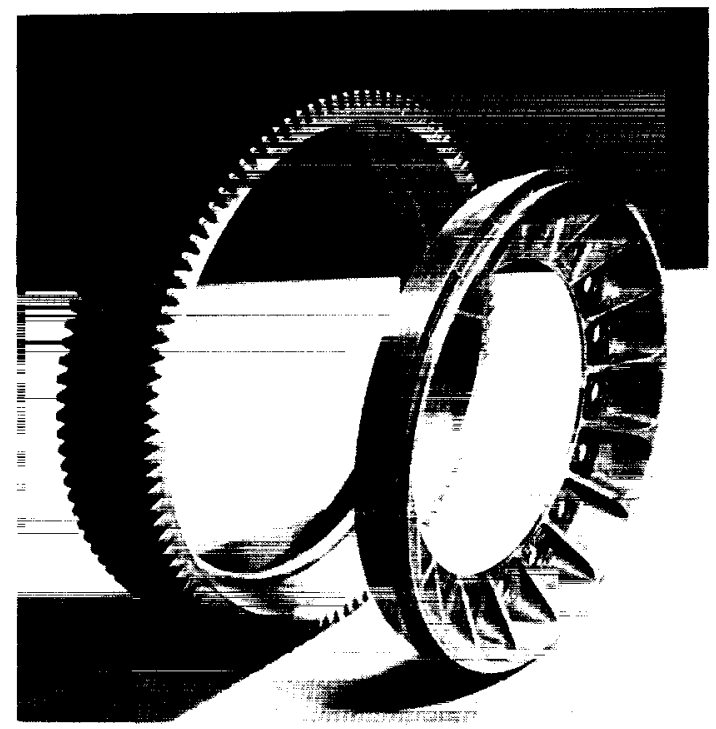

(b) Spur gear and isolator component.

Figure 5.-Elastomeric, torsionally compliant load sharing device.

ORIGINAL PAGE

BLACK AND WHITE PHOTOGRAPH

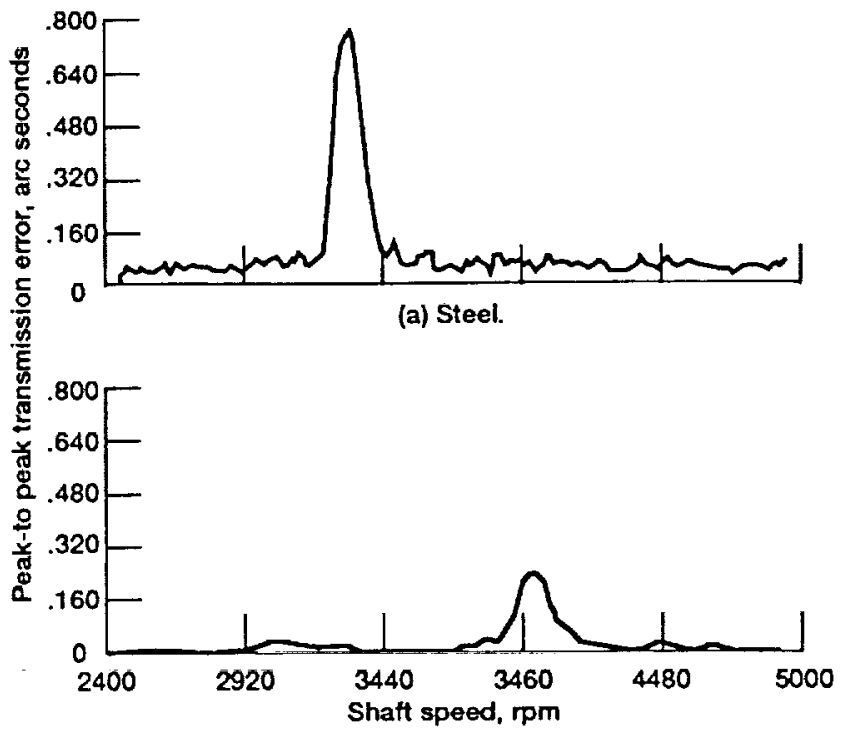

(b) Elastomer.

Figure 6.-Transmission error vs $\mathrm{mm}$ for upper helical mesh with and without elastomeric load sharing device installed.

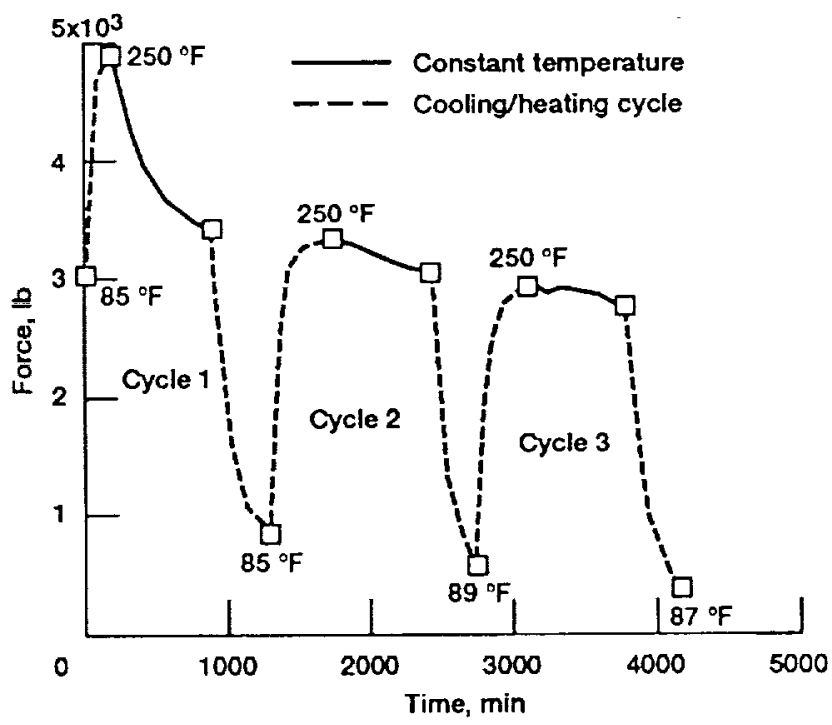

Figure 7.-Measured laminate compressive load vs time with temperature cycling and constant deflection. 


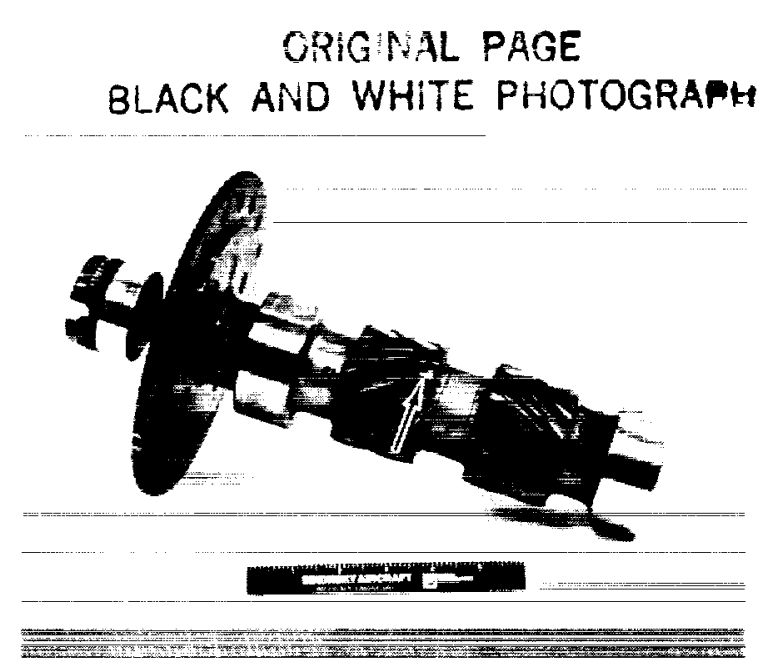

(a) Location of distress.

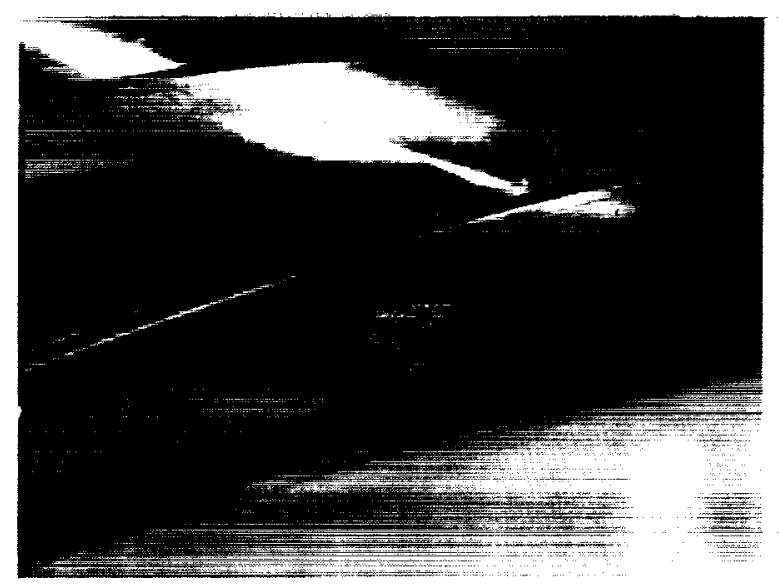

(b) First distress area.

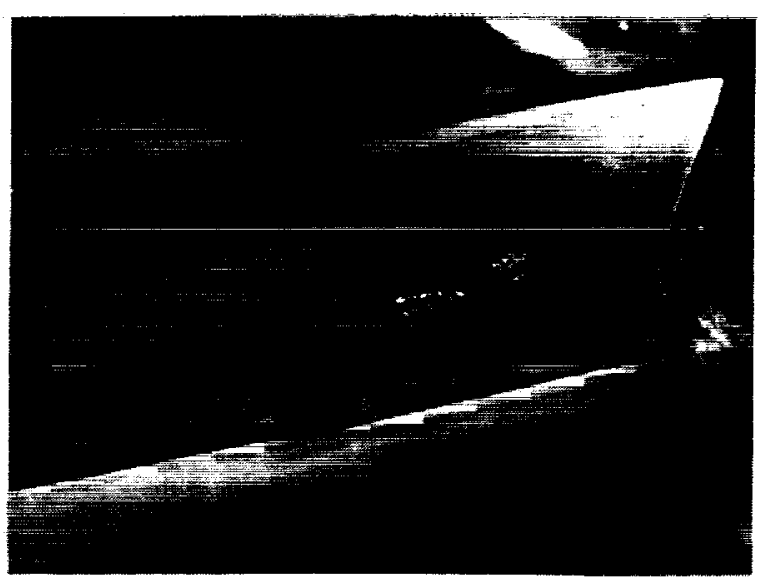

(c) Second distress area.

Figure 8.-Surface distress failure of double helical pinion.

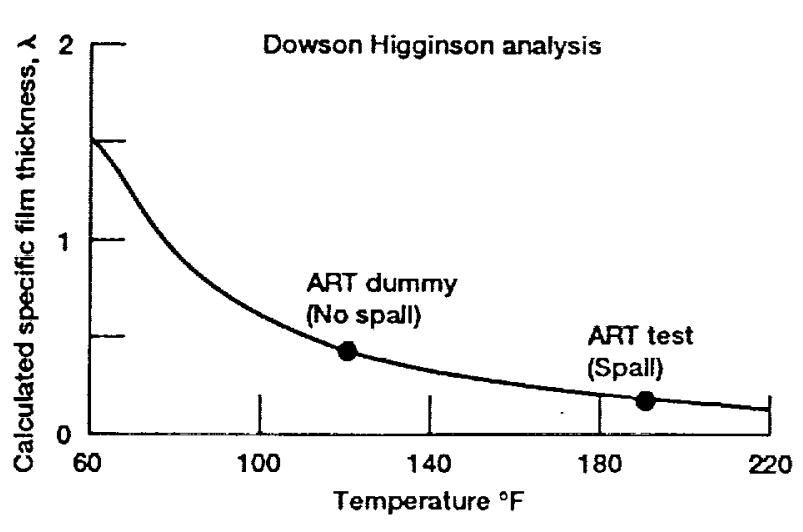

Figure 9. - Calculated specific film thickness, $\lambda$, vs temperature for ART 1/2 scale gearbox at full power.

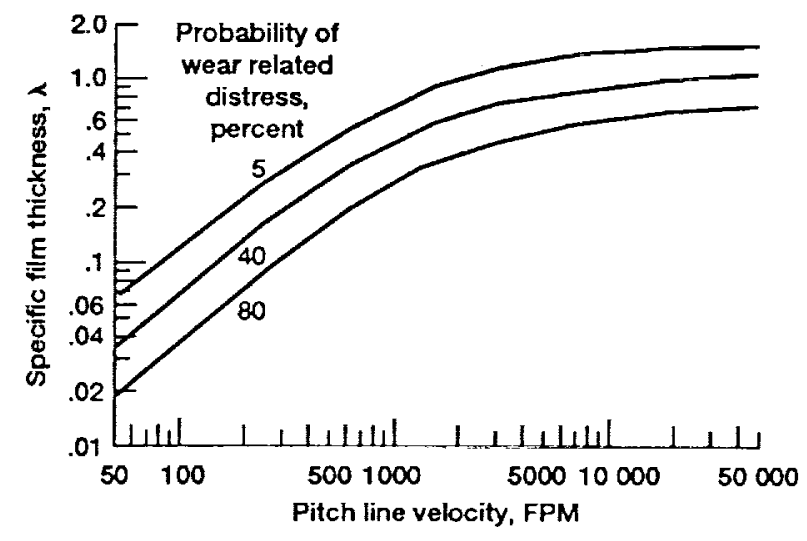

Figure 10.-Probability of Wear distress, percent. 




\begin{tabular}{|c|c|c|c|c|}
\hline \multicolumn{3}{|c|}{ REPORT DOCUMENTATION PAGE } & & $\begin{array}{l}\text { Form Approved } \\
\text { OMB No. 0704-0188 }\end{array}$ \\
\hline \multicolumn{5}{|c|}{ 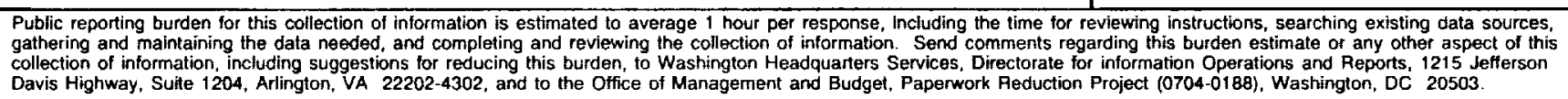 } \\
\hline 1. AGENCY USE ONLY (Leave blank) & $\begin{array}{r}\text { 2. REPORT DATE } \\
1992\end{array}$ & \multicolumn{3}{|c|}{$\begin{array}{l}\text { 3. REPORT TYPE AND DATES COVERED } \\
\text { Technical Memorandum }\end{array}$} \\
\hline \multicolumn{3}{|c|}{$\begin{array}{l}\text { 4. MTLE AND SUBTITE } \\
\text { Advanced Rotorcraft Transmission (ART) Program Summary }\end{array}$} & \multicolumn{2}{|c|}{ 5. FUNDING NUMBERS } \\
\hline $\begin{array}{l}\text { 6. AUTHOR(S) } \\
\text { T.L. Krantz and J.G. Kis }\end{array}$ & & & \multicolumn{2}{|c|}{$\begin{array}{l}\text { WU-505-63-36 } \\
1 \mathrm{~L} 162211 \mathrm{~A} 47 \mathrm{~A}\end{array}$} \\
\hline \multicolumn{3}{|c|}{$\begin{array}{l}\text { 7. PERFORMING ORGANIZATION NAME(S) AND ADDRESS(ES) } \\
\text { NASA Lewis Rescarch Center } \\
\text { Cleveland, Ohio } 44135-3191 \\
\text { and } \\
\text { Propulsion Directorate } \\
\text { U.S. Army Aviation Systems Command } \\
\text { Clcveland, Ohio } 44135-3191\end{array}$} & \multicolumn{2}{|c|}{$\begin{array}{l}\text { 8. PERFORMING ORGANIZATION } \\
\text { REPORT NUMBER }\end{array}$} \\
\hline \multicolumn{3}{|c|}{$\begin{array}{l}\text { National Acronautics and Space Administration } \\
\text { Washington, D.C. 20546-1001 } \\
\text { and } \\
\text { U.S. Army Aviation Systems Command } \\
\text { St. Louis, Mo. } 63120-1798\end{array}$} & \multicolumn{2}{|c|}{$\begin{array}{l}\text { NASA TM-105665 } \\
\text { AVSCOM-TR-92-C-011 } \\
\text { AIAA-92-3365 }\end{array}$} \\
\hline \multicolumn{5}{|c|}{$\begin{array}{l}\text { 11. SUPPLEMENTARY NOTES } \\
\text { Prepared for the } 28 \text { th Joint Propulsion Conference cosponsored by the AIAA, SAE, ASME, and ASEE, Nashville, } \\
\text { Tennessee, July 6-8, 1992. T.L. Krantz, Propulsion Directorate, U.S. Army Aviation Systems Command. J.G. Kish, } \\
\text { Sikorsky Aircraft, Stratford, Connecticut 06601-1381. Responsible person, T.L. Krantz, (216) 433-3580. }\end{array}$} \\
\hline \multicolumn{3}{|l|}{$\begin{array}{l}\text { Unclassified - Unlimited } \\
\text { Subject Category } 37\end{array}$} & \multicolumn{2}{|c|}{ 12b. DISTRIBUTION CODE } \\
\hline \multicolumn{5}{|c|}{$\begin{array}{l}\text { The Advanced Rotorcraft Transmission (ART) Program was initiated to advance the state-of-the-art for rotorcraft } \\
\text { transmissions. The goal of the ART Program was to develop and demonstrate the technologies needed to reduce } \\
\text { transmission weight by } 25 \text { percent and reduce noise by } 10 \mathrm{JB} \text { while obtaining a } 5000 \mathrm{hr} \text { mean-time-between-removal. This } \\
\text { paper summarizes the research done at Sikorsky Aircraft under the ART Program. A split path design was selected as best } \\
\text { able to meet the program goals. Key component technologies needed for this design were identified, studied, and } \\
\text { developed. Two of these technologies are discussed in detail: the load sharing of split path designs including the use of } \\
\text { a compliant elastomeric torque splitter and the application of a high ratio, low pitch line velocity gear mesh. Development } \\
\text { of an angular contact spherical roller bearing, transmission error analysis, and fretting fatigue testing are discussed. The } \\
\text { technologies for a lightweight, quiet, and reliable rotorcraft transmission have been demonstrated. }\end{array}$} \\
\hline \multirow{2}{*}{\multicolumn{3}{|c|}{$\begin{array}{l}\text { 14. SUBJECT TERMS } \\
\text { Helicopter transmission; Split torque; Gears; Gear lubrication }\end{array}$}} & & $\begin{array}{l}\text { 15. NUMBER OF PAGES } \\
14\end{array}$ \\
\hline & & & & $\begin{array}{l}\text { 16. PRICE CODE } \\
\text { A03 }\end{array}$ \\
\hline $\begin{array}{l}\text { 17. SECURTYY CLASSIFICATION } \\
\text { OF REPORT } \\
\text { Unclassified }\end{array}$ & $\begin{array}{l}\text { 18. SECURITY CLASSIFICATION } \\
\text { OF THIS PAGE }\end{array}$ & $\begin{array}{l}\text { 19. SECl } \\
\text { OF A }\end{array}$ & ION & 20. LIMITATION OF ABSTRACT \\
\hline Unclassified & Unclassified & & & \\
\hline
\end{tabular}

